\title{
Zinc deficiency and cellular oxidative stress: prognostic implications in cardiovascular diseases
}

\author{
Sangyong CHOI, Xian LIU, Zui PAN* \\ College of Nursing and Health Innovation, University of Texas at Arlington, Arlington, TX, USA
}

\begin{abstract}
Zinc is an essential nutrient for human health and has anti-oxidative stress and anti-inflammatory functions. The association between zinc deficiency and the development of cardiovascular diseases (CVDs) has been supported by numerous studies. Supplementing zinc can reduce the risk of atherosclerosis and protect against myocardial infarction and ischemia/reperfusion injury. In this review we summarize the evidence in the literature, to consolidate the current knowledge on the dysregulation of zinc homeostasis in CVDs, and to explore the significant roles of the zinc homeostasis-regulatory proteins in cardiac physiology and pathophysiology. Moreover, this review also deliberates on the potential diagnostic and prognostic implications of zinc/zinc homeostasis-associated molecules (ZIP, ZnT, and MTs) in CVDs.
\end{abstract}

Keywords: zinc homeostasis; zinc transporter (ZnT); Zrt; Irt-like protein (ZIP); metallothionein (MT); cardiovascular diseases; atherosclerosis; inflammation; ROS

Acta Pharmacologica Sinica (2018) 39: 1120-1132; doi: 10.1038/aps.2018.25; published online 7 Jun 2018

\section{Introduction}

The micronutrient zinc is essential to all living organisms and participates in numerous biochemical pathways in human cells. The human body mass contains 2-3 g of zinc, and approximately $57 \%$ and $29 \%$ of total body zinc exist in skeletal muscle and bone, respectively; heart and blood plasma are known to contain $0.4 \%$ and $0.1 \%$ of body zinc ${ }^{[1,2]}$. Inadequate intake, decreased absorption, or increased loss of zinc all can result in zinc deficiency. In experiment animals, severe zinc deficient diet led to $30 \%$ loss of body zinc ${ }^{[3]}$. In human body, severe zinc deficiency has serious impact, such as growth retardation, anemia, and neuronal dysfunctions; marginal zinc deficiency is associated with a broad spectrum of pathological conditions, especially aged-related ones including cardiovascular diseases (CVDs) ${ }^{[4]}$. Based on the estimated prevalence of zinc deficiency, the population with suboptimal zinc status ranges from $4 \%$ to $73 \%$ in different countries, and zinc deficiency may affect up to two billion people worldwide ${ }^{[5]}$.

Zinc carries out its multiple biological functions in several aspects. First, it is required by more than 300 enzymes for their catalytic activation, thus participating in various enzymatic and metabolic cellular processes in human body. Secondly,

\footnotetext{
*To whom correspondence should be addressed.

E-mail zui.pan@uta.edu

Received 2017-12-15 Accepted 2018-02-28
}

zinc binds to over 2500 proteins, equivalent to $10 \%$ of total human proteome, and maintains the structural integrity for many of them. For example, nitric oxide synthase (NOS), a family of metalloenzymes involved in blood pressure regulation and cardiovascular and renal functions, uses zinc for its structural stabilization ${ }^{[6]}$. This category also includes transcription factors, the DNA-binding proteins with zinc finger domains, copper/zinc superoxide dismutase, and various proteins involved in DNA repair. Thirdly, zinc as a metal ion may also directly regulate kinases, phosphatases, or channel activities $^{[4,7]}$. Collectively, zinc has a critical role in maintaining human health, especially in terms of anti-oxidative stress and anti-inflammation $^{[8]}$.

It remains to be a challenge to clearly determine zinc deficiency, especially marginal zinc deficiency. First of all, the common deficient signs of zinc nutrient are "multiple nonspecific general shifts in metabolism", including chronic oxidative stress and inflammation ${ }^{[9]}$. Secondly, zinc exists in various forms, and the changes in its concentration are dynamic. The plasma zinc turns over rapidly to supply different tissues and is replenished daily from diet. The intracellular zinc exists in three forms: tightly bound to proteins, loosely associated with protein or ligands, and unbound labile ions. Thirdly, the currently used indicators for zinc status are far from reliable. The widely accepted methods to evaluate zinc status and identify the risk of zinc deficiency are measuring plasma zinc concen- 
tration and monitoring dietary zinc intake, which neglect individual variability, poor sensitivity, and non-specificity ${ }^{[9]}$. There have been some attempts to adopt zinc status assessment with several combined indicators. A recent study identified the correlation of higher erythrocyte zinc concentration and urinary zinc excretion in population with metabolic syndrome, suggesting the importance of using several zinc indicators as a more reliable biomarker to better understand the relationship between the zinc nutrient and pathophysiological conditions $^{[10]}$.

CVD is a blanket term for a number of linked pathologies, including coronary artery and peripheral artery diseases and cerebrovascular diseases. It is a leading cause of death globally, accounting for $31 \%$ of human mortality. Many of these diseases are related to the process of atherosclerosis. It causes myocardial infarction (MI), stroke, and ischemia/reperfusion (I/R) injury. Other types of CVDs contain atrial fibrillation $(\mathrm{AF})$, chronic heart failure (CHF), and diabetic cardiovascular complications. Dyslipidemia, smoking, hypertension, and diabetes mellitus are well-known risk factors for these $\mathrm{CVDs}^{[11]}$. Many of these risk factors for CVDs are known to cause oxidative stress and induce inflammation.

Given the importance of zinc in anti-oxidative stress and anti-inflammation, it is not surprising to see that accumulating evidence has emerged, suggesting that zinc deficiency is associated with the development of CVDs, especially atherosclerosis, and zinc supplementation can protect against MI and I/ $\mathrm{R}$ injury. It would be of importance to establish the association between zinc status and various CVDs. The aim of this review is to summarize the evidence in the literature, to consolidate the current knowledge on such association, and to explore the significant roles of the zinc homeostasis-regulatory proteins in cardiac physiology and CVDs. Moreover, this review also deliberates about the potential prognostic implications of zinc/zinc homeostasis-associated molecules in CVDs.

\section{Antioxidant effects of zinc and redox signaling}

Oxidative stress is a key risk factor contributing to the development and progression of CVDs. Oxidative stress represents the status of imbalance between the production of free radicals and the ability of cells to detoxify, thus increasing oxidative damage to DNA, proteins, and lipids. Existing as a divalent cation in biological systems, although not redox active under physiological conditions, zinc is involved in multiple events regulating cell oxidant/antioxidant balance as an antioxidant or a signaling molecule ${ }^{[12]}$.

Many studies have shown an inverse-relationship between zinc availability and cellular oxidative stress. For example, zinc deficiency increases the production of reactive oxygen species (ROS) in various cells such as mouse 3T3 cells, rat C6 glioma cells, human fibroblasts, neuronal and epithelial cells ${ }^{[13]}$. In dietary zinc deficient animals, vascular smooth muscle cells (VSMCs) were also demonstrated to contain increased oxidative stress measured by fluorescent indicator $2^{\prime}, 7^{\prime}$-dichlorofluorescin diacetate (DCFDA) ${ }^{[14]}$. Moreover, a randomized controlled trial of zinc supplementation in elderly human subjects showed that this population had higher oxi- dative stress and lower plasma zinc levels than young adults; and the plasma lipid peroxidation markers were significantly decreased by zinc supplementation compared to the placebo group $^{[15]}$.

Since zinc is not redox active, the antioxidant function of zinc is through some indirect mechanisms of action (the mechanisms are reviewed elsewhere $\left.{ }^{[13,16-18]}\right)$. In mammalian cells, the main redox active metals, including copper and iron, catalyze the production of ROS and reactive nitrogen species (RNS), which are capable of oxidizing cellular components, such as lipid bilayer ${ }^{[19]}$. Zinc competes with these redox active metals for negative charges in lipid bilayer; and as such, it protects the cell membrane from lipid oxidation ${ }^{[20]}$. Zinc is also able to interact with thiol or sulfhydryl groups in proteins and peptides, to reduce the reactivity of sulfhydryl groups. This stabilization prevents intramolecular disulfide formation, and thus zinc functions as an antioxidant to protect these molecules from oxidation ${ }^{[18]}$. In addition, zinc can accelerate the synthesis of metallothioneins (MTs), a family of cysteinerich protein, via activating the zinc-sensing Metal regulatory Transcription Factor 1 (MTF-1) ${ }^{[21]}$. Since MTs are abundant in the cytosol, they provide more thiol groups and act as direct oxidant scavengers. Zinc also protects cells from oxidative stress by increasing glutathione (GSH) biosynthesis which is responsible for the maintenance of cellular redox state ${ }^{[22]}$.

Zinc additionally serves as a cofactor in antioxidant enzymes such as superoxide dismutase 1 (SOD1) that scavenges superoxide anions ${ }^{[23]}$. Although zinc is tightly incorporated in SOD1 and unlikely spontaneously released from the protein just because of changes in zinc status, there has been evidence to show that zinc supplementation affected SOD1 protein stability and protected mice bearing unstable SOD mutant gene ${ }^{[24]}$. Upon zinc depletion, SOD1 mutants underwent conformational changes due to zinc dissociation, which resulted in oxidative stress and endoplasmic reticulum (ER) stress $^{[25]}$. The excess oxidative stress caused by dysfunction of SOD1 or SOD3 can also react with nitric oxide (NO) to form RNS, which in turn oxidize endothelial nitric oxide synthase (eNOS) and uncouple functional eNOS dimers. Accumulating evidence has demonstrated that the eNOS dimer uncoupling increases pathologic ROS production and decreases NO synthesis by the endothelium ${ }^{[26]}$. Alternatively, superoxide could directly quench NO and thus reduce its bioavailability without affecting eNOS expression or activity in rat hearts ${ }^{[27]}$. Since $\mathrm{NO}$ is a key molecule controlling vasodilation, zinc deficiencycaused stress and reduction of NO are considered to play an important role in the pathogenesis of atherosclerosis and diabetic complications ${ }^{[28]}$, which will be discussed in detail in the following sections.

In another aspect of function, zinc participates in the redox signaling network by interacting with proteins. Oxidative stress can trigger zinc release from the binding sites, leading to conformational changes of these proteins. For example, Korichneva et al demonstrated that zinc was released from protein kinase $\mathrm{C}(\mathrm{PKC})$ during activation by ROS and was thus involved in the myocardial redox signaling network ${ }^{[12,29]}$. 


\section{Anti-inflammatory function of zinc}

Inflammation is another major risk factor contributing to the pathological process of CVDs. Zinc has been well known to be essential for the normal function of the immune system in both innate and adaptive immunity responding to pathogen or tissue damage. In general, zinc deficiency results in the impairment of antibody-mediated and cell-mediated immune response; however, it also causes increased auto-reactivity likely due to damaged immune tolerance and/or inefficient removal of autoreactive T-cells. In addition, zinc deficiency contributes to chronic inflammatory conditions, where no inducer appears to be required. These conditions are common and of particular interest since they coincide with and are likely to contribute to CVDs, type 2 diabetes (T2DM), and other chronic diseases ${ }^{[30]}$.

Two transcription factors serve as key modulators in the inflammatory response pathways: nuclear factor kappa-B (NF$\kappa B)$ and hypoxia-inducible factor-1 alpha (HIF-1a). Zinc status regulates both ${ }^{[30-32]}$. NF-kB mediates the central inflammatory signaling cascade $\mathrm{e}^{[33]}$. In unstimulated cells, NF- $\mathrm{KB}$ heterodimer ( $\mathrm{p} 65 / \mathrm{p} 50)$ is sequestered in the cytosol through the interactions with a class of inhibitory proteins called IкB (IкBa, $-\beta$, and $-\varepsilon$ ). Many stimuli induce NF-kB activation, such as tumor necrosis factor- $\alpha$ (TNF- $\alpha$ ), interleukin-1(IL-1), activators of PKC, ionizing radiation, and oxidants. These signals cause phosphorylation and subsequent degradation of ІкB proteins via the ubiquitination-proteasome pathway, and thereby, free $\mathrm{NF}-\mathrm{kB}$ can enter the nucleus and induce the expression of targeted genes. NF-kB-regulated genes contain many inflammatory cytokines, such as IL-1, IL-6, TNF-a, lymphotoxin, and interferon- $\gamma($ IFN- $\gamma)$. It is notable that IL-1 and TNF-a work to activate NF- $\mathrm{KB}$, therefore creating a feedback loop. Dietary zinc deficiency or intracellular zinc deprivation has been shown to result in increased activation of NF-kB and NF-kBregulated inflammatory cytokine expression in cultured cells, animal models, and humans ${ }^{[30,34]}$. Supplementation of zinc

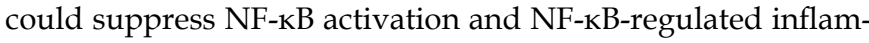
matory cytokine release likely through inhibiting the phosphorylation and degradation of IкB.

As a master regulator in hypoxia and ischemia, HIF-1 not only can rapidly respond to hypoxia, but also is activated by several non-hypoxic stimuli, such as inflammatory mediators or cytokines ${ }^{[35]}$. Since HIF-1 generally supports cell survival and the production of pro-inflammatory cytokines, it in turn further promotes angiogenesis, vascular remodeling, glucose metabolism, and redox homeostasis. Zinc has been shown to block hypoxia-stimulated HIF-1a nuclear translocation and subsequently disrupting HIF-1 heterodimerization as well as to induce HIF-1a proteasomal degradation ${ }^{[32]}$. On the other hand, zinc preconditioning can induce expression of HIF genes including HIF-1a in renal cells ${ }^{[36]}$. Therefore, zinc status may have different effects on HIF-1a in different cells at different inflammatory stages.

In brief, zinc deficiency affects the generation of inflammatory cytokines, including IL-1, IL-6, TNF- $a$, and IFN- $\gamma^{[37]}$. These zinc status-involved inflammatory responses often commingle with their antioxidant effects. For instance, zinc defi- ciency induced-oxidative stress results in the reduction of $\mathrm{NO}$ in epithelium; and NO, as an endogenous signaling molecule, has anti-inflammatory effects under normal physiological condition; and zinc is further involved in immune responses by cytokine-activated macrophages, which release NO in high concentrations.

\section{Zinc transporters and MTs in vascular and heart cells}

Intracellular zinc homeostasis is tightly regulated by two known classes of zinc transporters and MTs. Zrt, Irt-like protein (ZIP), encoded by solute carrier family 39 gene (SLC39A), functions in the uptake of zinc into the cytoplasm of cell from either the extracellular space or from intracellular organelles, such as endoplasmic reticulum, Golgi apparatus, and mitochondria $^{[38]}$. Zinc transporter (ZnT), encoded by solute carrier family 30 gene (SLC30A), moves zinc from the cytoplasm to the outside of the cell or into the lumen of intracellular organelles $^{[39]}$. There are 14 ZIPs and 10 ZnTs identified in human with differential tissue-specific expression.

As a family of highly conserved, low-molecular-weight, thiol-rich protein, MT binds zinc with high affinity and gathers about $5 \%-15 \%$ of the cytosolic zinc pool ${ }^{[40]}$. MT is genetically polymorphous with subfamilies and 12 isoforms. Each molecule of MT can incorporate up to 7 zinc ions or other divalent metals. In addition to its metal storage function, MTs can also work as zinc acceptors and donors to exchange the metal ion with other proteins in the cells via its reversible dissociation of zinc ions and oxidoreduction of the cysteine sulfur donors in zinc/thiolate clusters. Since the sulfur donors coordinating zinc in MTs are redox reactive, oxidation of the sulfur donors leads to the release of zinc, which contributes to overall intracellular zinc signaling. In addition, the interaction of MT with $\mathrm{NO}$ also controls the release of zinc and the availability of zinc to other apoenzymes involved in NO signaling.

Although the association study between altered zinc homeostasis and CVDs is emerging, the exact member(s) of the zinc transporters and isoform(s) of MTs expressed in normal vascular and heart cells are not very clear, let alone their biological roles in governing the overall zinc homeostasis under pathophysiological conditions ${ }^{[41]}$. Owing to the recent effort on Human Protein Atlas projects using a quantitative transcriptomics analysis (RNA-Seq) and antibody-based proteomics approach, we were able to extract data from these publicly available databases and compare the relative expression levels of the 24 zinc transporters and 12 MTs in heart tissues and vascular endothelial cells ${ }^{[42,43]}$. As shown in Figure 1A, SLC39A1, SLC39A7, SLC39A13, SLC39A14, and SLC30A9, which encode ZIP1, ZIP7, ZIP13, ZIP14, and ZnT9, respectively, are markedly abundant in human heart muscle tissues. Interestingly, these genes were also found to be abundant in rat ventricular myocytes although with slight variations in the zinc transporter profiles of rat and human myocardium ${ }^{[44]}$. In two human immortalized endothelial cell lines, ZIP1, ZIP13, and ZnT5 are the dominant zinc transporters expressed (Figure 1B). Different from heart and endothelial cells, smooth muscle cells contain abundant ZIP6 in addition to ZIP1 and ZIP13 as zinc influx transporters, while ZnT1, ZnT5, and ZnT9 are 

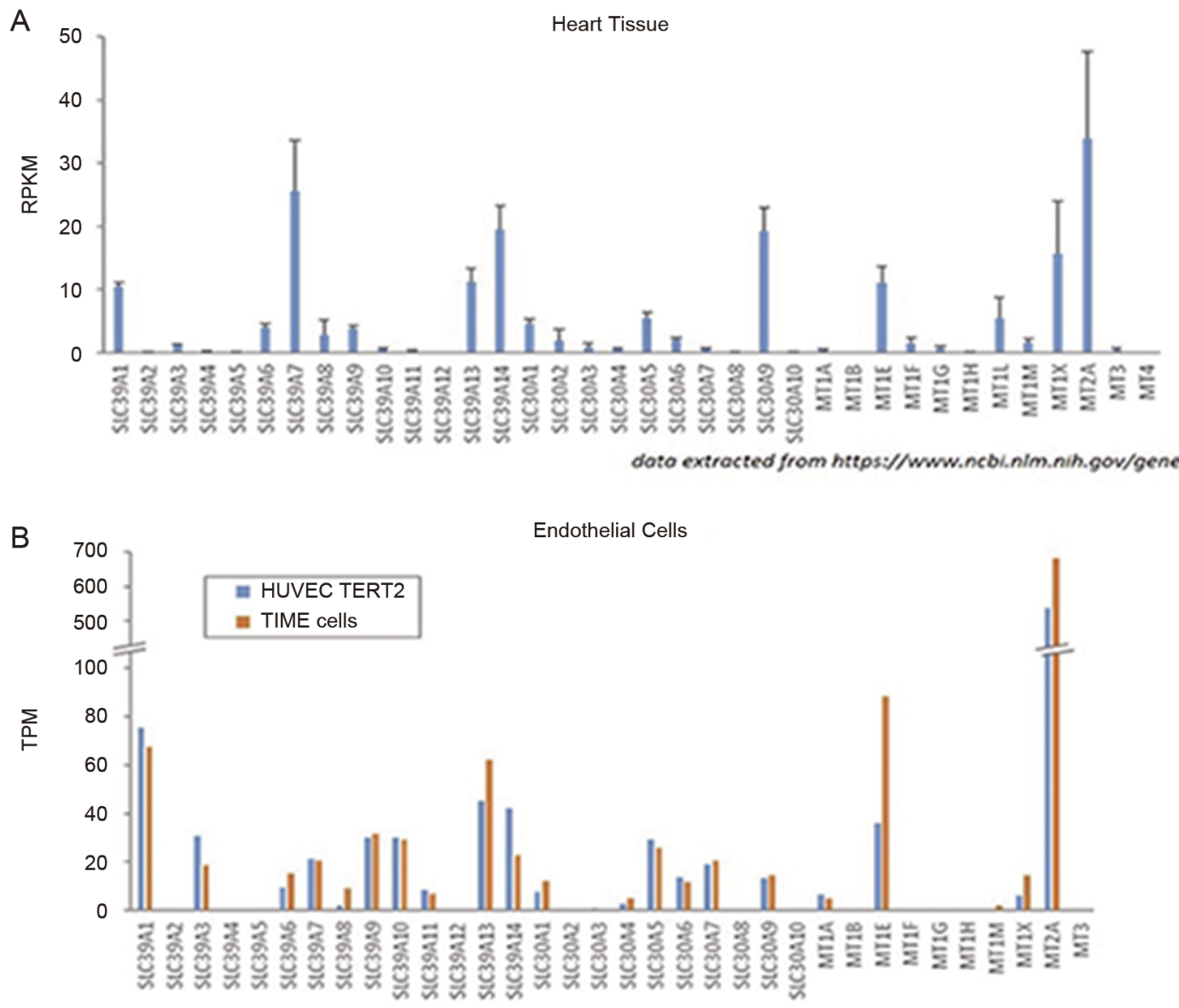

data extrocted from v27.proteinatlos.org

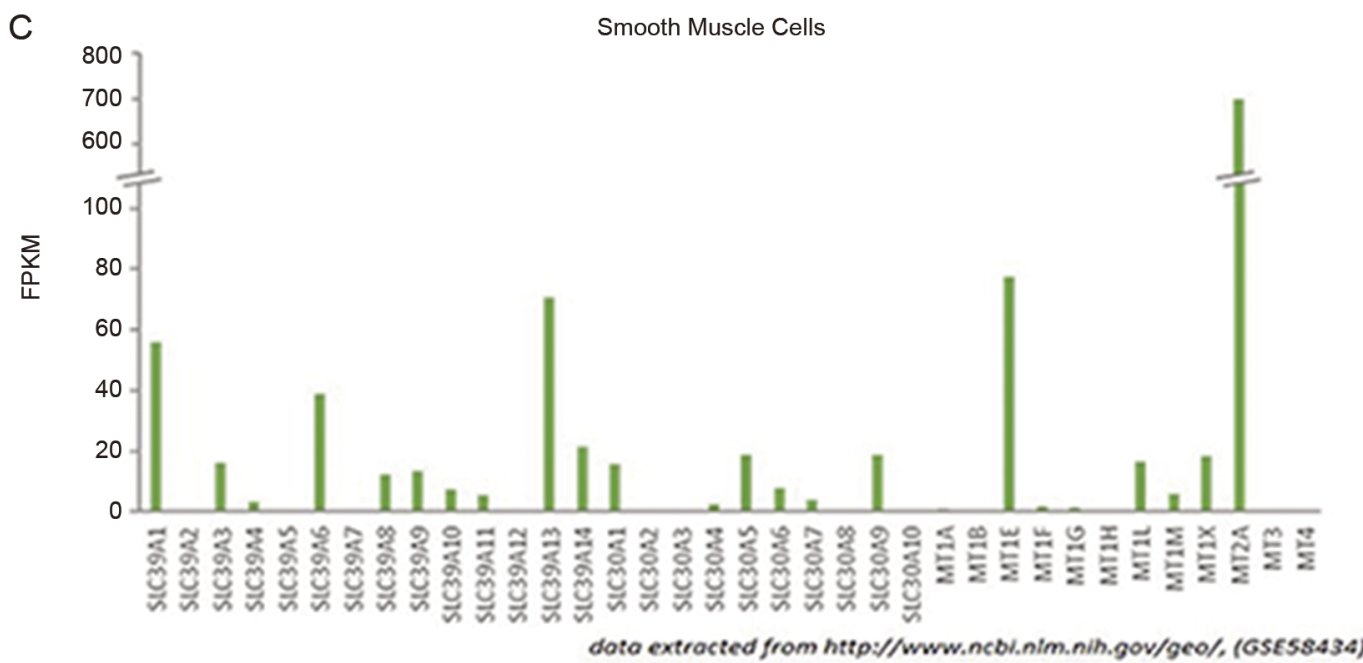

Figure 1. Expression levels of zinc transporters and MTs in heart and vascular cells. Data are extracted from publically available RNA-seq databases. (A) ZIPs, ZnTs, and MTs expression in human heart muscle tissue. Each gene's reads per kilobase per million reads placed (RPKM) was downloaded and examined for normal heart tissues. Error bars represent a standard deviation from RPKM values in four tissue samples. (B) ZIPs, ZnTs, and MTs expression in human endothelial cell lines. Transcript Per Million (TPM) of each gene was searched in RNA-seq data in Cell atlas section in Human Protein Atlas. Two bars in each gene represent HUVEC TERT2 (blue) and TIME cells (orange), respectively. (C) ZIPs, ZnTs, and MTs expression in human bronchial smooth muscle cells. Fragments per kilobase of transcript per million mapped reads (FPKM) value for each gene was obtained from the "Control Baseline" group in dataset GSE58434 at the Gene Expression Omnibus. 
abundant as zinc efflux transporters (Figure 1C) ${ }^{[45]}$. It has been reported that ZIP1 and ZIP14 localize to plasma membrane in rat cardiomyocytes, whereas ZIP7 and ZIP13 in the ER, Golgi, or cytoplasmic vesicles. The differences in their localization imply the characteristic roles of these zinc transporters in transferring zinc from either extracellular environment or lumen of intracellular compartments to the cell cytosol. ZIP14 is known to mobilize diverse metals including zinc, iron, and manganese. The precise function and metal specificity of ZIP14 in myocyte, however, has not been explored. ZnT9 is the most highly expressed in both human and rat hearts, suggesting its common role in the export of zinc out of myocytes.

In regard to MTs, their basal levels are usually very low, although they may vary depending upon the type of tissue or in response to aging or diseases. MT2A is the most abundant one in heart, smooth muscle, and endothelial cells, whereas MT1E and MT1X are with less abundance but still significantly expressed, suggesting their important functions in cardiovascular physiology. Accordingly, the polymorphisms of these genes are likely associated with various CVDs, which will be discussed in a later section separately.

\section{Zinc and atherosclerosis}

Atherosclerosis is the major cause of CVDs. It is characterized by plaque formation within the vessel wall of arteries, extensive apoptosis/necrosis, and fibrosis of surrounding tissues. Once the vulnerable plaque is raptured, the thrombotic vessels, especially small diameter vessels such as coronary arteries, can be occluded. Consequent heart attacks or strokes often result in sudden death or chronic heart failure/brain damage. The etiology of atherosclerosis has been extensively studied, and accumulating evidence demonstrates complex atherogenic process regulated by many factors from the metabolic, vascular, and immune systems. One of key characteristic traits of atherosclerosis is the increased oxidative stress, which results in endothelial damage/dysfunction, disturbed NO and NF-kB-related signaling, and the oxidative modification of low-density lipoprotein (LDL). As discussed earlier, zinc is

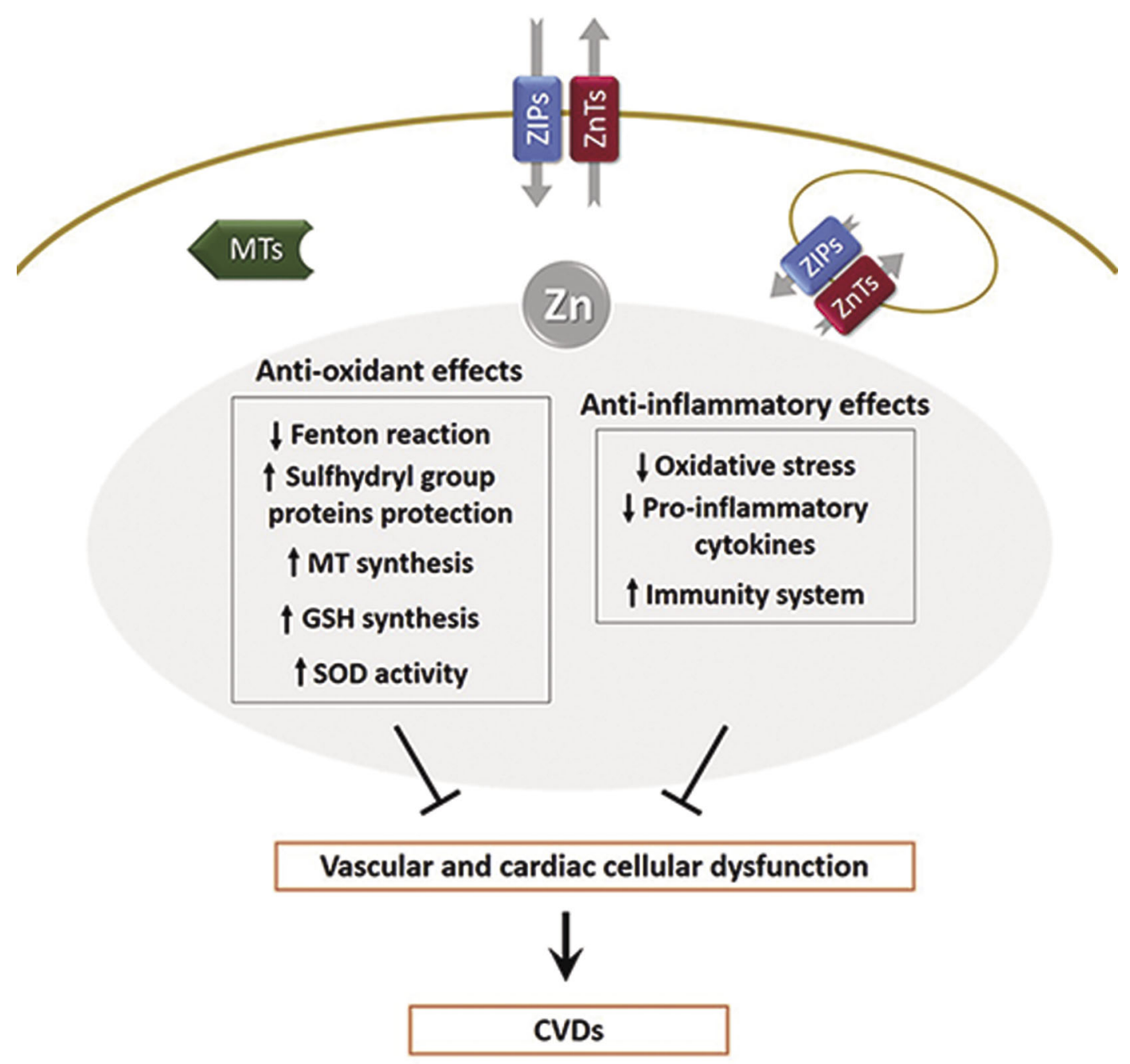

Figure 2. Schematic summary of key regulatory roles of zinc in CVDs. ZIPs and ZnTs are simply depicted to be localized in the cell plasma membrane and intracellular organelle membrane. MTs represents metallothionein proteins. 
involved in all these aspects mainly through its antioxidant and anti-inflammatory functions ${ }^{[46]}$. It is thus not a surprise to see that zinc regulates atherosclerotic process and zinc deficiency may be a strong risk factor for atherosclerosis.

\section{Animal and in vitro evidence}

Zinc deficiency has been shown to increase endothelial cell apoptosis and amplify the detrimental effects of oxidized LDL in atherosclerosis ${ }^{[47]}$. The nutrient deficiency can also activate the NOD-like receptor (NLR) family and pyrin domaincontaining 3 (NLRP3) inflammasome and induce IL-1 $\beta$ secretion in high fat diet-induced atherosclerosis animal model ${ }^{[48]}$, whereas zinc supplementation can inhibit NLRP3 inflammasome activation through its antioxidant effects in an in vitro study $^{[49]}$. Furthermore, Beattie et al studied suboptimal dietary zinc intake in a mouse model of atherosclerosis and found that zinc deficiency promoted vascular inflammation and arterial plaque formation ${ }^{[34]}$. Later, they also provided evidence to show that marginal dietary zinc deficiency in vivo induced vascular smooth muscle cell apoptosis; and long-term zinc deprivation, on the contrary, accelerated rat vascular smooth muscle cell proliferation through down-regulating c-Jun N-terminal kinase 1/2 (JNK1/2) expression in mitogen-activated protein kinase (MAPK) signaling pathway ${ }^{[14,50]}$.

These in vitro and animal studies provide strong evidence to link reduced zinc intake with increased plasma lipoprotein levels, increased smooth muscle remodeling, increased vascular inflammation, and plaques formation in mice consuming dietary zinc levels resembling human Western-type diet during the progression of atherosclerosis.

\section{Human studies}

Epidemiological evidence suggests that the progression of atherosclerosis is modified by nutritional factors including zinc $^{[51]}$. A number of studies reported that zinc deficiency could contribute to atherosclerosis ${ }^{[52]}$ and there was an inverse association between atherosclerosis and serum zinc levels, or rather the serum zinc/24-h urine zinc loss ratio ${ }^{[53,54]}$. According to the Biomarkers of Nutrition for Development (BOND) project, the dietary zinc intake record is recommended as one of the indicators to evaluate zinc levels in the human body ${ }^{[9]}$. Using carotid intima-media thickness (CIMT) as a valuable marker, the subclinical atherosclerosis was measured and explored for its relationship with the dietary zinc intake ${ }^{[55]}$. In the middle-aged and elderly populations, the low zinc intake group showed a higher CIMT than the high zinc intake group. The inverse correlation of zinc intake and atherosclerosis risk was also reported in another cross-sectional study ${ }^{[56]}$. Lower consumption of dietary zinc was associated with low highdensity lipoprotein (HDL) cholesterol levels as well as an increased prevalence of coronary artery disease. However, the association between zinc intake and the risk of atherosclerosis or other CVDs has not yet been confirmed by cohort or randomized clinical studies. Iowa Women's Health Study (IWHS) showed no significant inverse association between zinc intake and the mortality of CVDs including ischemic heart disease and stroke in overall study population, although it was the case in a high alcohol-intake group ${ }^{[57]}$. A very recent metaanalysis of randomized primary prevention trials also failed to show significant beneficial effects of the nutrient on CVDs ${ }^{[58]}$. It is worthwhile to point out that IWHS and these primary prevention trials used a combined supplement with multiple nutrients containing a relatively low dose of zinc $(\leq 20 \mathrm{mg} / \mathrm{d})$. Therefore, more well-designed studies with zinc supplementation are required to reveal the exact contribution of the zinc nutrient in CVDs. Many factors should be included into consideration, such as the interaction between zinc and other nutrients, and the actual bioavailability of zinc which is in a wide variety depending on one's genetic backgrounds and dietary patterns.

\section{Zinc status in CVDs}

The zinc level in heart tissues was found to be positively correlated with ejection fraction in human and distinctly localized to the sarcomere I-band ${ }^{[59,60]}$. Zinc also affects $\mathrm{Ca}^{2+}$ signaling that regulates versatile cellular responses in cardiomyocytes ${ }^{[61]}$. However, the exact function of zinc ions in normal heart physiology remains largely unknown. The changes in zinc status have been reported in various CVDs.

\section{Hypertension}

Loss of zinc homeostasis can be both the cause and effect of hypertension. A large amount of data from both clinical and animal studies has confirmed the altered distribution of zinc between the extracellular and intracellular spaces as well as tissue distribution in arterial hypertension ${ }^{[62]}$. Earlier studies found that there was a negative correlation between arterial blood pressure and zinc content in the serum and higher zinc concentration in the red blood cells in patients suffering from primary arterial hypertension. The concentrations of zinc were lower in the scalp hair and blood, but higher in the urine samples of hypertensive patients ${ }^{[63]}$. In a strain of spontaneously hypertensive rat, high zinc levels in erythrocytes and heart muscles were found, and zinc deficient diet could facilitate the development of hypertension likely through oxidative stress ${ }^{[64]}$. The detailed mechanisms underlying the association of zinc status and hypertension can be found elsewhere ${ }^{[47]}$. In pulmonary artery hypertension which is caused by chronic hypoxia and often leads to right ventricular hypertrophy, several recent studies demonstrated a significant elevation of intracellular labile zinc levels in both pulmonary endothelial cells and vascular smooth muscle cells ${ }^{[65,66]}$; however, the source for the labile zinc appeared to be different in these cells: zinc released from MTs upon NO activation and zinc influx through ZIP12, respectively.

\section{Myocardial infarction}

It has long been known that serum zinc level falls after acute tissue injury including MI. An earlier study showed that patients with MI showed a highly significant reduction in serum zinc within the first three days, compared to control or borderline groups ${ }^{[67]}$. The minimum serum zinc level and the peak value of serum enzymes, and also some other clinical MI estimators of prognosis are nicely correlated. Thus, it has been 
suggested that serum zinc is a reliable diagnostic indicator for acute MI, and the extent of the fall has prognostic implications. In a meta-analysis with 2886 subjects from 41 case-control studies, the authors revealed that the subjects with MI had lower zinc levels in serum and hair than healthy controls ${ }^{[68]}$. Moreover, a recent study using zinc quartiles also demonstrated a significant inverse correlation between serum zinc levels and serum creatine kinase (CK), CK-MB, and cardiac troponin T levels ${ }^{[69]}$. This study further showed the prevalence rate of MIs decreased with increasing zinc quartiles. Taken together, all data consistently suggest that serum zinc may work together with other cardiac markers as prognostic markers for MI.

In addition to its risk evaluation value, zinc also has a cardioprotective role for MI, at least well demonstrated in animal studies. In a MI dog model generated by left coronary artery branch occlusion, administration of zinc sulphate $(10 \mathrm{mg} / \mathrm{kg})$ hours before coronary occlusion significantly reduced the infarct size by almost half ${ }^{[70]}$. In two Langendorff perfused rat heart studies, administrating zinc with zinc ionophore pyrithione during reperfusion and maintaining high levels of cytosolic zinc by postconditioning greatly improved myocardial recovery after $I / R$ to almost $100 \%$, and decreased arrhythmias and infarct sizes more than two-fold ${ }^{[71,72]}$. This protective function of zinc is likely through preservation of PKC isoforms, and/or through reperfusion injury salvage kinase (RISK) pathway.

\section{Atrial fibrillation}

It is the common sustained cardiac arrhythmia associated with substantially increased morbidity and mortality. Many cases of AF occur in patients who have just received cardiac surgery ${ }^{[73]}$. A recent report demonstrated an inverse association between the plasma zinc concentrations during recovery period and the occurrence of postoperative AF in patients undergoing coronary artery bypass grafting ${ }^{[73]}$. Along with significant lower zinc concentrations at postoperative days 1 and 3 in AF patients, the patient group experiencing postoperative $\mathrm{AF}$ showed a slower recovery rate back to preoperative zinc level, compared to the group without AF. In a prospective study of 78 patients with clinically advanced congestive heart failure, serum zinc and copper levels did not show significant differences between patients with AF and those with sinus rhythm ${ }^{[7]}$. But both of these patient groups, compared to the healthy control group, showed significant hypozincemia (low blood zinc) and a decreased zinc/copper ratio in their serums.

\section{Congestive heart failure}

$\mathrm{CHF}$ is a progressive systemic illness accompanying with oxidative stress in multiple tissues and pro-inflammatory phenotypes. A disturbed homeostasis of micronutrients such as calcium, magnesium, zinc, selenium, and vitamin D, may contribute to the appearance of oxidative stress and to compromised endogenous anti-oxidative defenses to combat $\mathrm{CHF}^{[75]}$. Several studies showed an association between zinc deficiency and heart failure, such as in children with CHF and in patients with dilated cardiomyopathy ${ }^{[76,77]}$. Long-term treatment of multiple micronutrient supplements including magnesium, zinc, copper, selenium, and vitamins, improved left ventricular volumes, left ventricular ejection fraction, and quality of life in $\mathrm{CHF}$ patients.

Irrespective of the etiologic origins of $\mathrm{CHF}$, hypozincemia has been widely reported in patients with this disease ${ }^{[77]}$. While it is pointed out that low serum zinc is attributed to multiple factors, such as activation of the renin-angiotensinaldosterone system, CHF medications, and pathophysiological progress of $\mathrm{CHF}^{[77]}$, it is still unclear how much of the factors contribute to the hypozincemia in patients. For example, thiazide diuretics, which are widely used to treat hypertension by increasing urine flow, cause urinary zinc loss ${ }^{[46]}$. Other medications for $\mathrm{CHF}$, such as angiotensin converting enzyme inhibitors, angiotensin receptor blockers, and diuretic furosemide, can also lead to zinc deficiency ${ }^{[46]}$. Other underlying mechanisms for hypozincemia in CHF include decreased dietary zinc intake and/or impaired absorption in the small intestine, and increased zinc redistribution into the liver, muscle, and bone for storage $\mathrm{e}^{[75]}$.

\section{Zinc transporters and MTs in CVDs}

While zinc status itself is associated with many types of CVDs, zinc transporters and MTs may also play important roles in the pathological progress of these diseases. Table 1 is an attempt to summarize up-to-date known, although far from complete, zinc transporters and MTs involved.

\section{ZnTs and ZIPs}

There has been no report so far to show any direct link between zinc transporters and atherosclerosis. However, some recent evidence suggests such direction. Increased serum trimethylamine $\mathrm{N}$-oxide (TMAO), the product of gut microbiome and hepatic-mediated metabolism of dietary choline and $L$-carnitine, has recently been identified as a novel risk factor for the development of atherosclerosis in mice and humans ${ }^{[78]}$. A genome-wide association study identified a locus for TMAO levels on chromosome 3 that co-localized with a highly significant cis-expression quantitative trait locus for ZnT7 encoding gene, suggesting ZnT7 as a candidate gene responsible for the association signal with atherosclerosis. Future characterization on the specific role of ZnT7 in atherosclerosis will be required to address the question.

The first report revealing the roles of zinc transporters in ischemic heart diseases was from an in vitro study using adult mouse atrial cardiomyocyte HL-1 cells ${ }^{[79]}$. Beharier et al demonstrated that ZnT1 overexpression markedly decreased both lactate dehydrogenase (LDH) release and caspase activation following myocardial I/R, whereas knockdown of endogenous ZnT1 enhanced these I/R-induced activities. The cardioprotective function of ZnT1 is likely through its ability to interact with Raf-1 kinase, which regulates the extracellular signalregulated kinase (ERK) signaling pathway. It was recently reported that hypoxia increased the expression of ZnT1, but reoxygenation significantly increased the expression of ZnT2 and ZnT5, while ZnT9 expression remained unchanged in myocardial I/ $\mathrm{R}^{[44]}$. Interestingly, $\mathrm{ZnT} 9$ is more abundant, and 
Table 1. Zinc transporters and MTs in CVDs.

\begin{tabular}{|c|c|c|c|}
\hline Molecule & Changes/Data & Diseases & Ref. \\
\hline ZIP2 & Expression required for effects of postconditioning & I/R injury (cardioprotective effect of postconditioning) & {$[72]$} \\
\hline ZIP6 & Increase in RNA (1.3-1.7 fold; microarray, qRT-PCR) & Endothelial cell senescence (vascular pathology) & [103] \\
\hline ZIP7 & Increase in RNA (1.3 fold; microarray) & Endothelial cell senescence & [103] \\
\hline ZIP12 & Increase in RNA, protein(qRT-PCR, IHC) & Pulmonary hypertension (by hypoxia) & {$[66]$} \\
\hline ZIP13 & Increase in RNA (1.5 fold; microarray) & Endothelial cell senescence & [103] \\
\hline \multirow{2}{*}{ ZnT1 } & Increase in protein (WB) & I/R injury (hypoxia in cardiomyocytes) & {$[44]$} \\
\hline & Manipulation of expression adversely affects I/R injury & I/R injury (cardiomyocytes) & [79] \\
\hline ZnT2 & Increase in protein (WB) & I/R injury (hypoxia/reoxygeneration in cardiomyocytes) & {$[44]$} \\
\hline ZnT3 & Decrease in RNA (RT-PCR) & Vascular smooth muscle cell senescence (by angiotensin II) & {$[104]$} \\
\hline ZnT5 & Increase in protein (WB) & I/R injury (hypoxia/reoxygeneration in cardiomyocytes) & {$[44]$} \\
\hline ZnT6 & Decrease in RNA (1.4 fold; microarray) & Endothelial cell senescence & [103] \\
\hline \multirow{2}{*}{ ZnT8 } & rs13266634 (missense) & T2DM & {$[105]$} \\
\hline & Identified as autoantigen & T1DM & [91] \\
\hline ZnT10 & Decrease in RNA(RT-PCR) & Vascular smooth muscle cell senescence (by angiotensin II) & {$[104]$} \\
\hline MT-1A & rs8052394 (missense) & T2DM & {$[106]$} \\
\hline MT-1E & Increase in RNA (1.2 fold; microarray) & T2DM & {$[107]$} \\
\hline MT-1M & Increase in RNA (1.2 fold; microarray) & T2DM & {$[107]$} \\
\hline MT-1X & Increase in RNA (1.2 fold; microarray) & T2DM & {$[107]$} \\
\hline \multirow[t]{3}{*}{ MT-2A } & rs10636 (3'-UTR variant) & Atherosclerosis; carotid artery stenosis, coronary heart disease & {$[83-86]$} \\
\hline & rs1610216 (upstream variant) & T2DM with atherosclerosis & [84] \\
\hline & Increase in RNA (1.3 fold; microarray) & T2DM & {$[107]$} \\
\hline
\end{tabular}

ZnT1, ZnT2 and ZnT5 are much less abundant in the heart (Figure 1A). These data suggest that ZnT9 may be important to maintain normal cellular function of cardiomyocytes while the other ZnTs are involved in cellular response to hypoxia and reoxygenation.

Similar to ZnTs 1, ZnT2, and ZnT5, ZIP2 appears to have very low expression in heart tissues, smooth muscle cells, and endothelial cells (Figure 1). But it may respond to I/R injury in cardiomyocytes. A recent report showed that knockdown of ZIP2 partially attenuated the protective effect of postconditioning on $\mathrm{I} / \mathrm{R}$ injury in cardiac cells, pointing out that a normal level of ZIP2 is required for the protection of postconditioning $^{[72]}$. Since zinc deprivation alters multiple zinc transporters' expression at the mRNA level ${ }^{[80]}$, we speculate that other zinc transporters may be involved in myocardial I/R as well.

Beharier et al reported that acute rapid pacing of the rat atria increased the expression of ZnT1 that acted as an inhibitor of L-type calcium channel, in cultured cardiomyocytes or intact heart $^{[79]}$. Overexpression of ZnT1 decreased arrhythmogenic $\mathrm{Ca}^{2+}$ signals, while knockdown of ZnT1 enhanced the signals. Later, this group further demonstrated the increased ZnT1 expression in the atria of patients with $\mathrm{AF}^{[81]}$. Collectively, these data suggest that ZnT1 is a contributing factor for atrial tachycardia remodeling in patients with persistent AF.

\section{Metallothioneins}

The expression of MTs is dynamically regulated by oxidative stress and cellular zinc level ${ }^{[82]}$. MTs are perhaps more readily responsive to pathological changes in atherosclerosis than zinc transporters are. It has been well known that the persistence of oxidative stress and chronic pro-inflammatory cytokines exist in atherosclerosis. Indeed, MT gene expression is upregulated accompanying with the reduced zinc ion availability in peripheral blood mononuclear cells although those MT proteins may be in a less functional form as an antioxidant protein ${ }^{[83]}$. Furthermore, several novel MT polymorphisms have been identified in pathological process of atherosclerosis $^{[83-86]}$. Giacconi et al reported that the polymorphism at -209 A/G locus of MT2A gene (NCBI rs1610216) not only affects hyperglycemia and glycosylated hemoglobin in diabeticatherosclerotic patients, but also is associated with ischemic cardiomyopathy ${ }^{[84]}$. Another polymorphism of MT2A at +838 C/G (NCBI rs10636) in 3'-UTR region affects the susceptibility of atherosclerosis and carotid artery disease ${ }^{[83]}$.

Despite some earlier in vitro studies, the first evidence in intact animals suggesting $\mathrm{MT}^{\prime}$ s cardioprotective role in myocardia I/R injury was shown in a cardiac-specific MT-overexpressing transgenic mouse model ${ }^{[87]}$. Kang et al demonstrated that overexpression of MTs improved the recovery of cardiac contractile function and reduced infarct size in I/ R injured heart. Later studies further revealed that this protective function of MTs was achieved by suppressing oxidative stress and 
inhibiting apoptosis in cardiomyocytes.

\section{ZnT8 and MTs in diabetic cardiovascular complications}

Diabetes is classified as a chronic metabolic disease with two distinct forms: type 1 and type 2 . Type 1 is an autoimmune disease that destroys the insulin-producing pancreatic islet $\beta$-cells; and type 2 accounts for $>90 \%$ of all diabetes cases with adult-onset, although more and more cases are diagnosed in younger people. Both types of diabetes act as a major risk factor for CVDs, with $50 \%$ of diabetes-associated deaths resulting from cardiovascular complications ${ }^{[88]}$. Zinc has been known to play a key role in diabetes for more than 80 years. Back in the 1930s, it was already discovered that the pancreas of diabetic patients contained only half the amount of zinc compared to a healthy pancreas. Since then, a large amount of evidence has revealed the hormone-like functions of zinc ions in islet biology, the biochemistry of zinc in insulin synthesis, secretion and storage as well as the maintenance of the conformational integrity of insulin ${ }^{[89]}$.

Transporting zinc into the insulin secretory granules of $\beta$-cells is mainly through $\mathrm{ZnT}{ }^{[90]}$. Due to the importance of zinc for normal physiology of $\beta$-cells in healthy pancreas, any dysfunction of $\mathrm{ZnT}$ could result in serious consequences in insulin homeostasis. It has been discovered that autoantibodies against ZnT8 are major forms of autoantibodies in type 1 diabetes $(\mathrm{T} 1 \mathrm{DM})^{[91]}$, which is associated with antibody-mediated $\beta$-cell dysfunction and cytotoxicity. The mutations and polymorphism in ZnT8 have been linked to T2DM. Overexpression of ZnT8 increased insulin secretion in response to hyperglycemia in INS-1 insulin-secreting $\beta$-cells ${ }^{[92]}$. On the other hand, the $\beta$ cell-specific ZnT8-null mice displayed impaired morphology of $\beta$-cell granules and insulin processing as well as reduced first phase insulin secretion ${ }^{[93]}$. A non-synonymous single nucleotide polymorphism (SNP) (rs13266634 C>T) in ZnT8 is also associated with T2DM. This polymorphism contains an amino acid switch, where arginine at position 325 is replaced by tryptophan. This SNP disrupts the function of ZnT8 to transport zinc ions into the secretion granules where insulin is matured and formed to be zinc-bound hexameric structure ${ }^{[94]}$. Moreover, a recent study reported the loss-of-function mutations in SLC30A8 (ZnT8) gene locus from the sequencing and genotyping results of $\sim 150000$ individuals ${ }^{[95]}$. These loss-offunction mutations, interestingly, appear to protect human against T2DM. While the exact mechanism requires further investigation, these data nevertheless suggest that SNPs or mutations of ZnT8 may have prognostic value, and the targeted manipulation of the transporter may be a therapeutic strategy in diabetes prevention.

While ZnT8 is involved in diabetes through its role to transport zinc, dysfunction of MTs contributes to the pathology of diabetes mainly because of the reduced antioxidant and decreased radical species scavenging properties ${ }^{[96]}$. This notion has been well supported by many studies in diabetic animals. Overexpression of MT has been shown to reduce oxidative stress and DNA damage in $\beta$ cells of streptozotocin-induced diabetic mice, whereas knockout of MT1 and MT2 resulted in mild obesity and hyperleptinemia in mice ${ }^{[97,98]}$. In human subjects, the expression of MT can be significantly induced by zinc supplementation, and such induction reduces diabetic vascular complications ${ }^{[99]}$. In correspondence with this, T2DM patients with lower MT levels exhibited to be more susceptible to oxidative stress and hyperglycemia ${ }^{[100]}$. Similar as in atherosclerosis, some SNPs of MTs have also been associated with cardiovascular complications in T2DM. For example, the $\mathrm{C}+$ carriers of MT1A polymorphism +647 A/C (rs11640851) in T2DM patients displayed worse glycemic control, reduced zinc release from MT and higher MT production in PBMCs, suggesting the possible involvement of MT in diabetic cardiovascular complications ${ }^{[101]}$. More details for MTs polymorphisms can be found in a recent comprehensive review $\operatorname{article}^{[102]}$

\section{Conclusion and future directions}

Dysregulation of zinc metabolism is clearly associated with many CVDs. Since zinc concentration itself is not a good biomarker ${ }^{[4]}$, searching for a reliable, sensitive and specific biomarker to assess zinc status has been a research focus. One recently emerging method is the assessment of the expression of zinc transporters and/or zinc-binding proteins, such as MTs in circulating blood cells ${ }^{[108]}$. The advantage of using circulating blood cells, such as leukocytes, PBMC and erythrocytes, is their availability in routine clinical visits. Among a few tested zinc homeostasis pertinent proteins, eg, ZIP1, ZnT1, and MT, the expression of MT in leukocytes appears to be a preferred biomarker to assess zinc status, since it decreases in response to zinc depletion and increases in response to zinc supplementation in a dose-dependent manner. The changes in MT expression, moreover, respond to elevated amounts of dietary zinc at the earliest time point measured (2 days) ${ }^{[108]}$.

In addition to zinc status, the alteration in zinc transporters and MTs may have diagnostic and prognostic implications for CVDs directly (Table 1). Recent research in this area enthusiastically recognizes extracellular vesicles (EVs) from human liquid biopsy as intriguing sources to differentiate disease from healthy states ${ }^{[109,110]}$. These EV-based disease markers may be detected prior to the onset of symptoms, making them promising candidates for early stage of $\mathrm{CVDs}^{[109]}$. As heterogeneous populations of phospholipid bilayer-enclosed vesicles that are secreted into the extracellular space, EVs of endothelial or cardiac tissue origin have been found to contribute to CVDs ${ }^{[110]}$. Interestingly, some recent studies determined that the endothelial cell-derived exosomes indeed contained MT proteins responding to cellular stress conditions and EVs from various cells or human samples exhibited the presence of zinc transporters as well ${ }^{[111]}$. We do not yet understand the pathophysiological roles of these zinc transporters or MTs in EVs in CVDs. In order to fully examine the diagnostic and prognostic values of zinc transporters and MTs, future investigation on the association between EVs containing a specific zinc transporter(s) or MT(s) and CVDs is required.

\section{Abbreviations}

Cardiovascular disease (CVD); nitric oxide synthase (NOS); endothelial nitric oxide synthase (eNOS); reactive oxygen spe- 
cies (ROS); reactive nitrogen species (RNS); myocardial infarction (MI): vascular smooth muscle cells (VSMCs); metallothionein (MT); protein kinase C (PKC); glutathione (GSH); superoxide dismutase (SOD); endoplasmic reticulum (ER); nitric oxide (NO); type 2 diabetes (T2DM); type 1 diabetes (T1DM); nuclear factor kappa-B (NF-kB); hypoxia-inducible factor-1 alpha (HIF-1a); NF-кB light polypeptide gene enhancer in B-cells inhibitor (IKB); tumor necrosis factor- a (TNF-a); interleukin (IL); interferon (IFN); Zrt, Irt-like protein (ZIP); solute carrier family 39 (SLC39A); zinc transporter (ZnT); solute carrier family 30 (SLC30A); low-density lipoprotein (LDL); NODlike receptor (NLR); NLR Family Pyrin Domain Containing 3(NLRP3); c-Jun N-terminal kinase 1/2 (JNK1/2); mitogenactivated protein kinase (MAPK); carotid intima-media thickness (CIMT); high-density lipoprotein (HDL); creatine kinase (CK); reperfusion injury salvage kinases (RISK); atrial fibrillation (AF); congestive heart failure ( $\mathrm{CHF})$; trimethylamine N-oxide (TMAO); lactate dehydrogenase (LDH); ischemia/ reperfusion (I/R); extracellular signal-regulated kinase (ERK); single nucleotide polymorphism (SNP); untranslated region (UTR)

\section{References}

1 King JC, Shames DM, Woodhouse LR. Zinc homeostasis in humans. J Nutr 2000; 130: 1360S-6S.

2 Jackson MJ. Physiology of Zinc: general aspects. In: Mills CF, Editor. Zinc in human biology. London: Springer; 1989. p 1-14.

3 Jackson MJ, Jones DA, Edwards RH. Tissue zinc levels as an index of body zinc status. Clin Physiol 1982; 2: 333-43.

4 Pan Z, Choi S, Ouadid-Ahidouch H, Yang JM, Beattie JH, Korichneva I. Zinc transporters and dysregulated channels in cancers. Front Biosci (Landmark Ed) 2017; 22: 623-43.

5 Prasad AS. Discovery of human zinc deficiency: 50 years later. J Trace Elem Med Biol 2012; 26: 66-9.

6 Hemmens B, Goessler W, Schmidt K, Mayer B. Role of bound zinc in dimer stabilization but not enzyme activity of neuronal nitric-oxide synthase. J Biol Chem 2000; 275: 35786-91.

7 Choi S, Cui C, Luo Y, Kim SH, Ko JK, Huo X, et al. Selective inhibitory effects of zinc on cell proliferation in esophageal squamous cell carcinoma through Orai1. FASEB J 2018; 32: 404-16.

8 Prasad AS. Clinical, immunological, anti-inflammatory and antioxidant roles of zinc. Exp Gerontol 2008; 43: 370-7.

9 King JC, Brown KH, Gibson RS, Krebs NF, Lowe NM, Siekmann JH, et al. Biomarkers of nutrition for development (BOND)-Zinc review. J Nutr 2016; pii: jn220079.

10 Freitas EP, Cunha AT, Aquino SL, Pedrosa LF, Lima SC, Lima JG, et al. Zinc status biomarkers and cardiometabolic risk factors in metabolic syndrome: a case control study. Nutrients 2017; 9: pii: E175. doi: 10.3390/nu9020175.

11 Lorber D. Importance of cardiovascular disease risk management in patients with type 2 diabetes mellitus. Diabetes Metab Syndr Obes 2014; 7: 169-83.

12 Korichneva I. Zinc dynamics in the myocardial redox signaling network. Antioxid Redox Signal 2006; 8: 1707-21.

13 Eide DJ. The oxidative stress of zinc deficiency. Metallomics 2011; 3: 1124-9.

14 Allen-Redpath K, Ou O, Beattie JH, Kwun IS, Feldmann J, Nixon GF. Marginal dietary zinc deficiency in vivo induces vascular smooth muscle cell apoptosis in large arteries. Cardiovasc Res 2013; 99: 525-34.
15 Prasad AS, Beck FW, Bao B, Fitzgerald JT, Snell DC, Steinberg JD, et al. Zinc supplementation decreases incidence of infections in the elderly: effect of zinc on generation of cytokines and oxidative stress. Am J Clin Nutr 2007; 85: 837-44.

16 Oteiza PI. Zinc and the modulation of redox homeostasis. Free Radic Biol Med 2012; 53: 1748-59.

17 Marreiro DD, Cruz KJ, Morais JB, Beserra JB, Severo JS, de Oliveira AR. Zinc and oxidative stress: current mechanisms. Antioxidants (Basel) 2017; 6. pii: E24. doi: 10.3390/antiox6020024.

18 Bray TM, Bettger WJ. The physiological role of zinc as an antioxidant. Free Radic Biol Med 1990; 8: 281-91.

19 Stohs SJ, Bagchi D. Oxidative mechanisms in the toxicity of metal ions. Free Radic Biol Med 1995; 18: 321-36.

20 Zago MP, Oteiza PI. The antioxidant properties of zinc: interactions with iron and antioxidants. Free Radic Biol Med 2001; 31: 266-74.

21 Westin G, Schaffner W. A zinc-responsive factor interacts with a metal-regulated enhancer element (MRE) of the mouse metallothionein-I gene. EMBO J 1988; 7: 3763-70.

22 Cortese MM, Suschek CV, Wetzel W, Kroncke KD, Kolb-Bachofen V. Zinc protects endothelial cells from hydrogen peroxide via Nrf2dependent stimulation of glutathione biosynthesis. Free Radic Biol Med 2008; 44: 2002-12.

$23 \mathrm{Li} \mathrm{HT}$, Jiao M, Chen J, Liang Y. Roles of zinc and copper in modulating the oxidative refolding of bovine copper, zinc superoxide dismutase. Acta Biochim Biophys Sin (Shanghai) 2010; 42: 183-94.

24 Ermilova IP, Ermilov VB, Levy M, Ho E, Pereira C, Beckman JS. Protection by dietary zinc in ALS mutant G93A SOD transgenic mice. Neurosci Lett 2005; 379: 42-6.

25 Homma K, Fujisawa T, Tsuburaya N, Yamaguchi N, Kadowaki H, Takeda K, et al. SOD1 as a molecular switch for initiating the homeostatic ER stress response under zinc deficiency. Mol Cell 2013; 52: 75-86.

26 Forstermann U, Li H. Therapeutic effect of enhancing endothelial nitric oxide synthase (eNOS) expression and preventing eNOS uncoupling. Br J Pharmacol 2011; 164: 213-23.

27 Paolocci N, Biondi R, Bettini M, Lee Cl, Berlowitz CO, Rossi R, et al. Oxygen radical-mediated reduction in basal and agonist-evoked NO release in isolated rat heart. J Mol Cell Cardiol 2001; 33: 671-9.

28 Chistiakov DA, Sobenin IA, Orekhov AN, Bobryshev YV. Role of endoplasmic reticulum stress in atherosclerosis and diabetic macrovascular complications. Biomed Res Int 2014; 2014: 610140.

29 Korichneva I, Hoyos B, Chua R, Levi E, Hammerling U. Zinc release from protein kinase $C$ as the common event during activation by lipid second messenger or reactive oxygen. J Biol Chem 2002; 277: 44327-31.

30 Wong $\mathrm{CP}$, Ho E. Zinc and its role in age-related inflammation and immune dysfunction. Mol Nutr Food Res 2012; 56: 77-87.

31 Bao S, Liu MJ, Lee B, Besecker B, Lai JP, Guttridge DC, et al. Zinc modulates the innate immune response in vivo to polymicrobial sepsis through regulation of NF-kappaB. Am J Physiol Lung Cell Mol Physiol 2010; 298: L744-54.

32 Nardinocchi L, Pantisano V, Puca R, Porru M, Aiello A, Grasselli A, et al. Zinc downregulates HIF-1alpha and inhibits its activity in tumor cells in vitro and in vivo. PLoS One 2010; 5: e15048.

33 Lawrence T. The nuclear factor NF-kappaB pathway in inflammation. Cold Spring Harb Perspect Biol 2009; 1: a001651.

34 Beattie JH, Gordon MJ, Duthie SJ, McNeil CJ, Horgan GW, Nixon GF, et al. Suboptimal dietary zinc intake promotes vascular inflammation and atherogenesis in a mouse model of atherosclerosis. Mol Nutr Food Res 2012; 56: 1097-105.

35 Palazon A, Goldrath AW, Nizet V, Johnson RS. HIF transcription factors, inflammation, and immunity. Immunity 2014; 41: 518-28. 
36 Rao K, Sethi K, Ischia J, Gibson L, Galea L, Xiao L, et al. Protective effect of zinc preconditioning against renal ischemia reperfusion injury is dose dependent. PLoS One 2017; 12: e0180028.

37 Foster M, Samman S. Zinc and regulation of inflammatory cytokines: implications for cardiometabolic disease. Nutrients 2012; 4: 67694.

38 Jeong J, Eide DJ. The SLC39 family of zinc transporters. Mol Aspects Med 2013; 34: 612-9.

39 Choi S, Bird AJ. Zinc'ing sensibly: controlling zinc homeostasis at the transcriptional level. Metallomics 2014; 6: 1198-215.

40 Coyle P, Philcox JC, Carey LC, Rofe AM. Metallothionein: the multipurpose protein. Cell Mol Life Sci 2002; 59: 627-47.

41 Lichten LA, Cousins RJ. Mammalian zinc transporters: nutritional and physiologic regulation. Annu Rev Nutr 2009; 29: 153-76.

42 Fagerberg L, Hallstrom BM, Oksvold P, Kampf C, Djureinovic D, Odeberg $\mathrm{J}$, et al. Analysis of the human tissue-specific expression by genome-wide integration of transcriptomics and antibody-based proteomics. Mol Cell Proteomics 2014; 13: 397-406.

43 Thul PJ, Akesson L, Wiking M, Mahdessian D, Geladaki A, Ait Blal H, et al. A subcellular map of the human proteome. Science 2017; 356. pii: eaal3321. doi: 10.1126/science.aal3321.

44 Bodiga VL, Thokala S, Kovur SM, Bodiga S. Zinc dyshomeostasis in cardiomyocytes after acute hypoxia/reoxygenation. Biol Trace Elem Res 2017; 179: 117-29.

45 Himes BE, Koziol-White C, Johnson M, Nikolos C, Jester W, Klanderman $\mathrm{B}$, et al. Vitamin $\mathrm{D}$ modulates expression of the airway smooth muscle transcriptome in fatal asthma. PLoS One 2015; 10 : e0134057.

46 Little PJ, Bhattacharya R, Moreyra AE, Korichneva IL. Zinc and cardiovascular disease. Nutrition 2010; 26: 1050-7.

47 Foster M, Samman S. Zinc and redox signaling: perturbations associated with cardiovascular disease and diabetes mellitus. Antioxid Redox Signal 2010; 13: 1549-73.

48 Summersgill H, England H, Lopez-Castejon G, Lawrence CB, Luheshi $\mathrm{NM}$, Pahle J, et al. Zinc depletion regulates the processing and secretion of IL-1beta. Cell Death Dis 2014; 5: e1040.

49 Fan Y, Zhang XL, Yang LN, Wang J, Hu Y, Bian AS, et al. Zinc inhibits high glucose-induced NLRP3 inflammasome activation in human peritoneal mesothelial cells. Mol Med Rep 2017; 16: 5195-202.

50 Alcantara EH, Shin MY, Feldmann J, Nixon GF, Beattie JH, Kwun IS. Long-term zinc deprivation accelerates rat vascular smooth muscle cell proliferation involving the down-regulation of JNK1/2 expression in MAPK signaling. Atherosclerosis 2013; 228: 46-52.

51 Kritchevsky D. Diet and atherosclerosis. J Nutr Health Aging 2001; 5: 155-9.

52 Beattie JH, Kwun IS. Is zinc deficiency a risk factor for atherosclerosis? Br J Nutr 2004; 91: 177-81.

53 Atsumi T, Numano F. Blood zinc levels in patients with arteriosclerosis obliterans, thromboangiitis obliterans and Takayasu's disease. Jpn Heart J 1975; 16: 664-9.

54 Giannoglou GD, Konstantinou DM, Kovatsi L, Chatzizisis YS, Mikhailidis DP. Association of reduced zinc status with angiographically severe coronary atherosclerosis: a pilot study. Angiology 2010; 61: 449-55.

55 Yang YJ, Choi BY, Chun BY, Kweon SS, Lee YH, Park PS, et al. Dietary zinc intake is inversely related to subclinical atherosclerosis measured by carotid intima-media thickness. Br J Nutr 2010; 104: 1202-11.

56 Singh RB, Niaz MA, Rastogi SS, Bajaj S, Zhang GL, Zhu SM. Current zinc intake and risk of diabetes and coronary artery disease and factors associated with insulin resistance in rural and urban populations of north India. J Am Coll Nutr 1998; 17: 564-70.
57 Lee DH, Folsom AR, Jacobs DR. Iron, zinc, and alcohol consumption and mortality from cardiovascular diseases: the lowa Women's Health Study. Am J Clin Nutr 2005; 81: 787-91.

58 Schwingshackl L, Boeing $\mathrm{H}$, Stelmach-Mardas M, Gottschald M, Dietrich S, Hoffmann G, et al. Dietary supplements and risk of causespecific death, cardiovascular disease, and cancer: a systematic review and meta-analysis of primary prevention trials. Adv Nutr 2017; 8: 27-39.

59 Oster O, Dahm M, Oelert H. Element concentrations (selenium, copper, zinc, iron, magnesium, potassium, phosphorous) in heart tissue of patients with coronary heart disease correlated with physiological parameters of the heart. Eur Heart J 1993; 14: 770-4.

60 Palmer BM, Vogt S, Chen Z, Lachapelle RR, Lewinter MM. Intracellular distributions of essential elements in cardiomyocytes. J Struct Biol 2006; 155: 12-21.

61 Yi T, Vick JS, Vecchio MJ, Begin KJ, Bell SP, Delay RJ, et al. Identifying cellular mechanisms of zinc-induced relaxation in isolated cardiomyocytes. Am J Physiol Heart Circ Physiol 2013; 305: H70615.

62 Tubek S. Selected zinc metabolism parameters in women with arterial hypotension. Biol Trace Elem Res 2007; 116: 73-9.

63 Afridi HI, Kazi TG, Talpur FN, Kazi A, Arain SS, Arain SA, et al. Interaction between essential elements selenium and zinc with cadmium and mercury in samples from hypertensive patients. Biol Trace Elem Res 2014; 160: 185-96.

64 Sato M, Yanagisawa H, Nojima Y, Tamura J, Wada O. Zn deficiency aggravates hypertension in spontaneously hypertensive rats: possible role of $\mathrm{Cu} / \mathrm{Zn}$-superoxide dismutase. Clin Exp Hypertens 2002; 24: 355-70.

65 Bernal PJ, Leelavanichkul K, Bauer E, Cao R, Wilson A, Wasserloos $\mathrm{KJ}$, et al. Nitric-oxide-mediated zinc release contributes to hypoxic regulation of pulmonary vascular tone. Circ Res 2008; 102: 157583.

66 Zhao L, Oliver E, Maratou K, Atanur SS, Dubois OD, Cotroneo E, et al. The zinc transporter ZIP12 regulates the pulmonary vascular response to chronic hypoxia. Nature 2015; 524: 356-60.

67 Low WI, Ikram H. Plasma zinc in acute myocardial infarction. Diagnostic and prognostic implications. Br Heart J 1976; 38: 133942.

68 Liu B, Cai ZQ, Zhou YM. Deficient zinc levels and myocardial infarction: association between deficient zinc levels and myocardial infarction: a meta-analysis. Biol Trace Elem Res 2015; 165: 41-50.

69 Huang L, Teng T, Zhao J, Bian B, Yao W, Yu X, et al. The relationship between serum zinc levels, cardiac markers and the risk of acute myocardial infarction by zinc quartiles. Heart Lung Circ 2018; 27 : 66-72. doi: 10.1016/j.hlc.2017.01.022.

70 Lal A. Effect of zinc sulphate on infarct size in experimental myocardial infarction in dogs. Indian J Med Res 1991; 94: 316-9.

71 Karagulova G, Yue Y, Moreyra A, Boutjdir M, Korichneva I. Protective role of intracellular zinc in myocardial ischemia/reperfusion is associated with preservation of protein kinase $C$ isoforms. J Pharmacol Exp Ther 2007; 321: 517-25.

$72 \mathrm{Xu} \mathrm{Z}$, Kim S, Huh J. Zinc plays a critical role in the cardioprotective effect of postconditioning by enhancing the activation of the RISK pathway in rat hearts. J Mol Cell Cardiol 2014; 66: 12-7.

73 Yan YQ, Zou LJ. Relation between zinc, copper, and magnesium concentrations following cardiopulmonary bypass and postoperative atrial fibrillation in patients undergoing coronary artery bypass grafting. Biol Trace Elem Res 2012; 148: 148-53.

74 Ghaemian A, Salehifar E, Jalalian R, Ghasemi F, Azizi S, Masoumi S, et al. Zinc and copper levels in severe heart failure and the effects of atrial fibrillation on the zinc and copper status. Biol Trace Elem Res 
2011; 143: 1239-46.

75 Kamalov G, Holewinski JP, Bhattacharya SK, Ahokas RA, Sun Y, Gerling IC, et al. Nutrient dyshomeostasis in congestive heart failure. Am J Med Sci 2009; 338: 28-33.

76 Cohen N, Golik A. Zinc balance and medications commonly used in the management of heart failure. Heart Fail Rev 2006; 11: 19-24.

77 Efeovbokhan N, Bhattacharya SK, Ahokas RA, Sun Y, Guntaka RV, Gerling IC, et al. Zinc and the prooxidant heart failure phenotype. J Cardiovasc Pharmacol 2014; 64: 393-400.

78 Hartiala J, Bennett BJ, Tang WH, Wang Z, Stewart AF, Roberts R, et al. Comparative genome-wide association studies in mice and humans for trimethylamine $\mathrm{N}$-oxide, a proatherogenic metabolite of choline and L-carnitine. Arterioscler Thromb Vasc Biol 2014; 34: 1307-13.

79 Beharier O, Dror S, Levy S, Kahn J, Mor M, Etzion S, et al. ZnT-1 protects $\mathrm{HL}-1$ cells from simulated ischemia-reperfusion through activation of Ras-ERK signaling. J Mol Med (Berl) 2012; 90: 127-38.

80 Cousins RJ, Blanchard RK, Popp MP, Liu L, Cao J, Moore JB, et al. A global view of the selectivity of zinc deprivation and excess on genes expressed in human THP-1 mononuclear cells. Proc Natl Acad Sci U S A 2003; 100: 6952-7.

81 Etzion Y, Ganiel A, Beharier O, Shalev A, Novack V, Volvich L, et al. Correlation between atrial ZnT-1 expression and atrial fibrillation in humans: a pilot study. J Cardiovasc Electrophysiol 2008; 19: 157 64.

82 Cousins RJ, Liuzzi JP, Lichten LA. Mammalian zinc transport, trafficking, and signals. J Biol Chem 2006; 281: 24085-9.

83 Giacconi R, Caruso C, Malavolta M, Lio D, Balistreri CR, Scola L, et al. Pro-inflammatory genetic background and zinc status in old atherosclerotic subjects. Ageing Res Rev 2008; 7: 306-18.

84 Giacconi R, Cipriano C, Muti E, Costarelli L, Maurizio C, Saba V, et al. Novel -209A/G MT2A polymorphism in old patients with type 2 diabetes and atherosclerosis: relationship with inflammation (IL-6) and zinc. Biogerontology 2005; 6: 407-13.

85 Giacconi R, Muti E, Malavolta M, Cipriano C, Costarelli L, Bernardini $\mathrm{G}$, et al. The $+838 \mathrm{C} / \mathrm{G} \mathrm{MT2A}$ polymorphism, metals, and the inflammatory/immune response in carotid artery stenosis in elderly people. Mol Med 2007; 13: 388-95.

86 Yang $\mathrm{XY}$, Sun JH, Ke HY, Chen YJ, Xu M, Luo GH. Metallothionein 2A genetic polymorphism and its correlation to coronary heart disease. Eur Rev Med Pharmacol Sci 2014; 18: 3747-53.

87 Kang YJ, Li G, Saari JT. Metallothionein inhibits ischemia-reperfusion injury in mouse heart. Am J Physiol 1999; 276: H993-7.

88 DiSilvestro RA. Zinc in relation to diabetes and oxidative disease. J Nutr 2000; 130: 1509S-11S.

89 Vallee BL. Biochemistry, physiology and pathology of zinc. Physiol Rev 1959; 39: 443-90.

90 Shan Z, Bao W, Zhang Y, Rong Y, Wang X, Jin Y, et al. Interactions between zinc transporter-8 gene (SLC3OA8) and plasma zinc concentrations for impaired glucose regulation and type 2 diabetes. Diabetes 2014; 63: 1796-803.

91 Wenzlau JM, Juhl K, Yu L, Moua O, Sarkar SA, Gottlieb P, et al. The cation efflux transporter ZnT8 (SIc30A8) is a major autoantigen in human type 1 diabetes. Proc Natl Acad Sci U S A 2007; 104: 17040-5.

92 Chimienti F, Devergnas S, Pattou F, Schuit F, Garcia-Cuenca $\mathrm{R}$, Vandewalle $\mathrm{B}$, et al. In vivo expression and functional characterization of the zinc transporter ZnT8 in glucose-induced insulin secretion. J Cell Sci 2006; 119: 4199-206.

93 Wijesekara N, Dai FF, Hardy AB, Giglou PR, Bhattacharjee A, Koshkin V, et al. Beta cell-specific Znt8 deletion in mice causes marked defects in insulin processing, crystallisation and secretion. Diabetologia 2010; 53: 1656-68.
94 Nicolson TJ, Bellomo EA, Wijesekara N, Loder MK, Baldwin JM, Gyulkhandanyan AV, et al. Insulin storage and glucose homeostasis in mice null for the granule zinc transporter ZnT8 and studies of the type 2 diabetes-associated variants. Diabetes 2009; 58: 2070-83.

95 Flannick J, Thorleifsson G, Beer NL, Jacobs SB, Grarup N, Burtt NP, et al. Loss-of-function mutations in SLC30A8 protect against type 2 diabetes. Nat Genet 2014; 46: 357-63.

96 Maret W. Redox biochemistry of mammalian metallothioneins. J Biol Inorg Chem 2011; 16: 1079-86.

97 Chen H, Carlson EC, Pellet L, Moritz JT, Epstein PN. Overexpression of metallothionein in pancreatic beta-cells reduces streptozotocininduced DNA damage and diabetes. Diabetes 2001; 50: 2040-6.

98 Beattie JH, Wood AM, Newman AM, Bremner I, Choo KH, Michalska $\mathrm{AE}$, et al. Obesity and hyperleptinemia in metallothionein (-I and $-\mathrm{II})$ null mice. Proc Natl Acad Sci U S A 1998; 95: 358-63.

99 Wang J, Song Y, Elsherif L, Song Z, Zhou G, Prabhu SD, et al. Cardiac metallothionein induction plays the major role in the prevention of diabetic cardiomyopathy by zinc supplementation. Circulation 2006; 113: 544-54.

100 Maret W, Krezel A. Cellular zinc and redox buffering capacity of metallothionein/thionein in health and disease. Mol Med 2007; 13 : 371-5.

101 Giacconi R, Bonfigli AR, Testa R, Sirolla C, Cipriano C, Marra M, et al. $+647 \mathrm{~A} / \mathrm{C}$ and $+1245 \mathrm{MT} 1 \mathrm{~A}$ polymorphisms in the susceptibility of diabetes mellitus and cardiovascular complications. Mol Genet Metab 2008; 94: 98-104.

102 Raudenska M, Gumulec J, Podlaha O, Sztalmachova M, Babula P, Eckschlager T, et al. Metallothionein polymorphisms in pathological processes. Metallomics 2014; 6: 55-68.

103 Malavolta M, Costarelli L, Giacconi R, Basso A, Piacenza F, Pierpaoli E, et al. Changes in $\mathrm{Zn}$ homeostasis during long term culture of primary endothelial cells and effects of $\mathrm{Zn}$ on endothelial cell senescence. Exp Gerontol 2017; 99: 35-45.

104 Patrushev N, Seidel-Rogol B, Salazar G. Angiotensin II requires zinc and downregulation of the zinc transporters ZnT3 and ZnT10 to induce senescence of vascular smooth muscle cells. PLoS One 2012; 7: e33211.

105 Sladek R, Rocheleau G, Rung J, Dina C, Shen L, Serre D, et al. A genome-wide association study identifies novel risk loci for type 2 diabetes. Nature 2007; 445: 881-5.

106 Yang L, Li H, Yu T, Zhao H, Cherian MG, Cai L, et al. Polymorphisms in metallothionein-1 and -2 genes associated with the risk of type 2 diabetes mellitus and its complications. Am J Physiol Endocrinol Metab 2008; 294: E987-92.

107 Marselli L, Thorne J, Dahiya S, Sgroi DC, Sharma A, Bonner-Weir S, et al. Gene expression profiles of Beta-cell enriched tissue obtained by laser capture microdissection from subjects with type 2 diabetes. PLoS One 2010; 5: e11499.

108 Hennigar SR, Kelley AM, McClung JP. Metallothionein and Zinc transporter expression in circulating human blood cells as biomarkers of Zinc status: a systematic review. Adv Nutr 2016; 7: 735-46.

109 Jansen F, Nickenig G, Werner N. Extracellular vesicles in cardiovascular disease: potential applications in diagnosis, prognosis, and epidemiology. Circ Res 2017; 120: 1649-57.

110 Hromada C, Muhleder S, Grillari J, Redl H, Holnthoner W. Endothelial extracellular vesicles-promises and challenges. Front Physiol 2017; 8: 275.

111 de Jong OG, Verhaar MC, Chen Y, Vader P, Gremmels H, Posthuma G, et al. Cellular stress conditions are reflected in the protein and RNA content of endothelial cell-derived exosomes. J Extracell Vesicles 2012; 1. 
(a) This work is licensed under the Creative

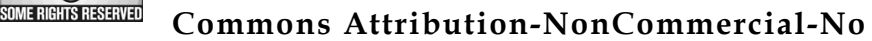
Derivative Works 3.0 Unported License. To view a copy of this license, visit http://creativecommons.org/licenses/ by-nc-nd/3.0/

(c) The Author(s) 2018 